\title{
A SAÚDE MENTAL DOS PROFISSIONAIS DA SAÚDE E O PROGRAMA DE EDUCAÇÃO PELO TRABALHO
}

\author{
MENTAL HEALTH OF HEALTH PROFESSIONALS AND THE EDUCATION FOR WORK PROGRAM \\ LA SALUD MENTAL DE LOS PROFESIONALES DE LA SALUD Y EL PROGRAMA DE EDUCACIÓN \\ A TRAVÉS DEL TRABAJO
}

\author{
Eloísa Cerutti Martellet ${ }^{1}$ \\ Roberta Fin Motta ${ }^{2}$ \\ Adriana Dornelles Carpes ${ }^{3}$
}

Resumo Estudo qualitativo que teve por objetivo abordar o cuidado aos profissionais que atuam em unidades de saúde, sobretudo os impactos, os significados e as relações no trabalho, além da vulnerabilidade ao estresse do trabalho. A pesquisa foi realizada na cidade de Santa Maria, estado do Rio Grande do Sul, com amostra de 14 participantes de cinco unidades de saúde. Os dados foram coletados por meio de entrevistas, observações e testagem, e, posteriormente, analisados mediante a análise de conteúdo. Como resultado, o trabalho apresenta-se de forma ora estruturante, ou seja, um operador fundamental na constituição do sujeito, ora desestruturante, capaz de desestabilizar a identidade e a personalidade e causar doenças mentais. As motivações, a relação com a comunidade e o diálogo nas relações de trabalho, bem como a necessidade de ações com os profissionais de saúde, na perspectiva de cuidar da saúde de quem cuida, foram percebidas como fundamentais na relação saúde mental e trabalho.

Palavras-chave subjetividade; saúde; trabalho; educação.
Abstract This qualitative study aimed to address the care given to professionals who work at health care units, particularly the impacts, meanings and relationships at work, in addition to vulnerability to stress at work. The survey was conducted in the city of Santa Maria, state of Rio Grande do Sul (Brazil), with a sample of 14 participants from five health care units. The data were collected through interviews, observations and testing, and, subsequently, analyzed using content analysis. As a result, at times the work appears to be structuring, i.e., a key operator in the constitution of the subject, while at others deconstructive, able to destabilize one's identity and personality and cause mental illness. The motivations, the relationship with the community, and the dialog in labor relations, as well as the need for actions with the health professionals, from the perspective of caring for the caregivers' health, were perceived as fundamental in the relationship between mental health and work.

Keywords subjectivity; health; work; education. 


\section{Introdução}

O Programa de Ensino pelo Trabalho para a Saúde (PET-Saúde) é um projeto do governo federal que tem por objetivo fomentar a formação de grupos de aprendizagem tutorial em áreas estratégicas para o Sistema Único de Saúde (SUS). Caracteriza-se como um instrumento para a qualificação em serviço dos profissionais da saúde, bem como de iniciação ao trabalho e suas vivências. É dirigido aos estudantes das graduações em saúde, de acordo com as necessidades do SUS. Visa fortalecer a integração dos cursos da saúde das instituições superiores de ensino (IESs) com os serviços da rede municipal de saúde, proporcionando uma formação acadêmica interdisciplinar, contextualizada e resolutiva voltada para a intersetorialidade dos serviços de atenção à saúde individual e coletiva (Brasil, 2010).

O PET-Saúde da cidade de Santa Maria, Rio Grande do Sul, é constituído por uma parceria entre duas instituições de ensino superior (IESs), uma privada e outra pública, e o governo federal. Esse projeto é integrado por onze cursos superiores, dentre eles nove cursos da área de Ciências da Saúde (Biomedicina, Enfermagem, Farmácia, Fisioterapia, Fonoaudiologia, Medicina, Nutrição, Odontologia e Terapia Ocupacional) e dois cursos da área de Ciências Humanas (Psicologia e Serviço Social). Intitulado “Ações integradas do ensino-serviço na atenção básica e assistência farmacêutica no município de Santa Maria-RS", o projeto-base desmembra-se em outros projetos, subdivisões por cursos e áreas de trabalho. O projeto vinculado ao Curso de Psicologia teve o enfoque voltado para a relação entre trabalho e saúde do trabalhador, especificamente dos profissionais da área da saúde que atuavam em unidades de saúde contempladas pelo PET-Saúde.

A psicologia do trabalho é uma área relativamente nova, que, até se estabelecer, passou por três momentos diferentes. Nas duas primeiras fases, a psicologia do trabalho esteve a serviço das instituições, focada exclusivamente no aumento da produtividade e dos lucros, e desempenhando principalmente atividades de recrutamento, seleção e treinamento, a fim de adequar o funcionário à empresa. Entretanto, em seu momento atual, a psicologia do trabalho passou por intenso e determinante progresso, mediante o qual agregou aos papéis desempenhados anteriormente a saúde mental daquele que trabalha, as relações, o significado do trabalho e suas manifestações em cada indivíduo, considerando a forma individual e coletiva, dinamizando as organizações de trabalho, que eram rígidas, e pensando, então, na relação entre o homem e o mundo do trabalho (Sampaio, 1998).

Por ser esse um tema pertencente ao campo da saúde coletiva, para se trabalhar essa relação, devem ser conjugados muitos fatores. Assim, ao se pensar em saúde do trabalhador, é preciso pensar esse trabalhador por 
inteiro, biopsicossocialmente, contemplando promoção da saúde, prevenção da doença, assistência à reabilitação e vigilância em saúde.

Apesar de cada área ter as suas especificidades, o tema exige um trabalho conjunto, a inter-relação de diversos saberes e a apreensão de múltiplos conceitos. Utilizam-se tradicionalmente informações produzidas por outros setores, como os registros da Previdência Social e dados do Ministério do Trabalho e Emprego, dentre outros, mas há carência de dados nos serviços de saúde relativos ao nexo causal entre trabalho e saúde/doença mental considerando o contexto laboral, a subjetividade do trabalhador e a relação que há entre os dois, reafirmando a importância de pesquisar o assunto (Centro de Referência Técnica em Psicologia e Políticas Públicas, 2008).

A prática psicológica em saúde do trabalhador vai além do olhar sobre a relação do homem com a sua atividade, a forma como ele se insere no processo produtivo, as condições da organização e a divisão do trabalho. $\mathrm{O}$ que diferencia a prática psicológica das outras práticas é o reconhecimento da subjetividade no trabalho, o significado que os indivíduos atribuem a determinadas situações, o modo como cada um reage diante dos desafios no ambiente de trabalho, o que sofre a inferência da história de vida, valores, crenças, experiências e representações que cada sujeito tem sobre a atividade desenvolvida. A psicologia considera o sujeito, resgatando seus conhecimentos e valorizando a subjetividade dos trabalhadores para compreender melhor suas práticas de trabalho (Centro de Referência Técnica em Psicologia e Políticas Públicas, 2008).

De acordo com Dejours (1992), autor referência nos estudos sobre trabalho na área da psicologia e para este artigo, a organização do trabalho exerce uma ação específica sobre o homem, com impacto no aparelho psíquico. Por organização do trabalho, o autor compreende a divisão do trabalho, a forma de conhecer os conteúdos das tarefas, bem como a divisão entre os trabalhadores, o sistema hierárquico, as modalidades de comando, as relações de poder e as questões de responsabilidade.

Segundo o mesmo autor, há sofrimento quando a relação entre a organização e o trabalhador é bloqueada, isto é, quando há uma rigidez determinada pela organização e o homem já não pode fazer modificações em suas tarefas conforme as suas necessidades fisiológicas e seus desejos. Nesse caso, a organização do trabalho pode comprometer o equilíbrio psicossomático, e quanto mais rígida a organização do trabalho, menos ela facilitará estruturações favoráveis à economia psicossomática individual. Logo, o estabelecimento de formas rígidas de trabalho que desconsideram a contribuição e a capacidade de criação do homem é um grande desencadeador de adoecimento psíquico, pois torna os trabalhadores incapazes de conhecerem a própria significação de seu trabalho em relação ao conjunto da atividade - e, mais do que isso, a sua significação humana. Nesse caso, a 
vivência depressiva se alimenta da sensação de adoecimento intelectual e de paralisia da imaginação, e marca o triunfo do adoecimento. Outro fator que contribuiria para o adoecimento é a aceleração dos tempos, a exigência de desempenhos produtivos, de rendimento crescente, o que conduziria os indivíduos a descompensações rápidas que, muitas vezes, podem levar a epidemias (Dejours, 1992).

Então, diante desses sofrimentos, o homem desenvolve estratégias de defesa, meios utilizados para se proteger e não estar completamente exposto e sujeito à organização de trabalho. Apesar de cada sujeito identificar os sentimentos no trabalho de forma singular, uma vez que são experiências subjetivas, é possível que os trabalhadores unidos possam mobilizar esforços coletivamente e construir uma estratégia defensiva comum. Desse modo, o sofrimento funcionaria como elemento popular e criativo, contribuindo para beneficiar a identidade do trabalhador, podendo ser canalizado a fim de aumentar a resistência do trabalhador à desestabilização psíquica e social (Dejours, Abdoucheli e Jayet, 1994).

Além disso, Dejours (1992) destaca que o trabalho pode também ser uma fonte favorável à saúde do corpo e da mente, um meio de relaxamento que faria o trabalhador sentir-se melhor durante o processo de produção do que ao ver a sua tarefa terminada. Segundo o autor, isso ocorre quando o trabalho pode ser livremente escolhido ou livremente organizado pelo trabalhador, quando ele pode adaptar as suas condições e funções intelectuais, motoras e psicossensoriais às tarefas a serem desempenhadas, adequando com isso a organização do trabalho e a sua estrutura mental.

Assim, o trabalho desperta sentimentos no trabalhador, e as relações no trabalho mobilizam investimentos afetivos como amor, ódio, amizade, solidariedade, confiança, entre outros. Algumas vezes o trabalho, por determinados fatores, passa a mobilizar sentimentos negativos no trabalhador que podem levá-lo ao sofrimento e, a partir disso, a desenvolver recursos para suportar e não adoecer em decorrência das pressões psíquicas da atividade (Dejours, 2006).

\section{Metodologia}

A pesquisa ${ }^{4}$ caracterizou-se por ser de tipo exploratório, estruturada com base numa abordagem qualitativa e quantitativa. De acordo com Minayo (2008), na pesquisa qualitativa os dados coletados são analisados por meio do significado que os sujeitos e/ou o pesquisador atribuem a eles, podendo também ocorrer participação do pesquisador no processo de obtenção das informações. Nas pesquisas quantitativas em psicologia, busca-se uma visão prática e objetiva, transformando os dados obtidos em valores numé- 
ricos para, posteriormente, realizar um tratamento de ordem matemático-estatístico que permita a rejeição ou a aceitação das hipóteses levantadas (Scarparo, 2008).

Assim, foram realizadas entrevistas semiestruturadas, contendo questões relacionadas aos objetivos da pesquisa. As entrevistas foram gravadas e posteriormente transcritas na íntegra. Além disso, foram realizadas observações participantes nos locais de trabalho durante as quais se fizeram anotações em diário de campo, com a finalidade de não se perderem informações valiosas e relevantes (Leopardi et al., 2002). Juntamente com os outros instrumentos citados, foi aplicado o Teste Psicológico Escala de Vulnerabilidade ao Estresse no Trabalho (Event), que teve por objetivo avaliar, de forma psicométrica, a vulnerabilidade ao estresse ao trabalho; o teste psicológico Event foi analisado de acordo com o seu manual. A escolha desse teste se deu por ser um material de fácil acesso e compreensão, além de coletar dados que vinham ao encontro da proposta do estudo. É um teste bastante completo, por abranger três importantes variáveis do trabalho que influenciam diretamente na saúde do trabalhador: clima e funcionamento organizacional; pressão no trabalho; e infraestrutura e rotina. Quanto à validação, pela análise de componentes iniciais, rotação varimax, foram extraídas, assim, as três variáveis citadas. A escala avalia o quanto as circunstâncias do cotidiano do trabalho influenciam na conduta das pessoas, a ponto de causar alguma fragilidade.

As entrevistas, as aplicações do teste e as observações foram realizadas concomitantemente, com o intuito de adquirir maior fidedignidade de dados. A partir dessas leituras, foi desenvolvida a análise de conteúdo, quando os dados coletados foram organizados, divididos e sintetizados, com o propósito de identificar as partes em comum para assim construir as categorias temáticas mais representativas. (Bardin, 2004).

Os participantes da pesquisa foram profissionais de saúde de cinco unidades de saúde. Três dessas unidades eram da Estratégia Saúde da Família (ESF) e duas eram unidades básicas de saúde (UBSs) da cidade de Santa Maria, Rio Grande do Sul. Essas unidades de saúde faziam parte do Programa de Educação pelo Trabalho para a Saúde (PET-Saúde). A pesquisa contou com uma amostra de 14 participantes.

Para a realização desta pesquisa foram respeitados os critérios éticos necessários em pesquisas com seres humanos, conforme preconizam as Diretrizes e Normas de Pesquisas em Seres Humanos, segundo a resolução n. 466, de 12 de dezembro de 2012, do Conselho Nacional de Saúde (Brasil, 2012). Após a devida autorização dos órgãos responsáveis, sob registro n. 0768/2009/SMS/Nepes, tiveram início as atividades da pesquisa. 


\section{Resultados e discussão}

A pesquisa foi realizada com 14 profissionais da saúde das unidades de saúde elencadas pelo PET-Saúde. No Quadro 1, são apresentadas características dos participantes da pesquisa: idade, gênero, tipo de unidade de saúde, profissão e tempo de serviço no local.

Quadro 1

\begin{tabular}{|c|c|c|c|c|c|}
\hline \multicolumn{6}{|c|}{ Caracterização dos participantes da pesquisa } \\
\hline Participante & Gênero & $\begin{array}{c}\text { Idade } \\
\text { (em anos) }\end{array}$ & $\begin{array}{l}\text { Unidade de } \\
\text { saúde (US) }\end{array}$ & Profissão & $\begin{array}{l}\text { Unidade de } \\
\text { saúde (US) }\end{array}$ \\
\hline A & $\mathrm{F}$ & 26 & ESF & Enfermeira & 2 \\
\hline B & $\mathrm{F}$ & 27 & ESF & Médica & 2 \\
\hline C & $\mathrm{F}$ & 33 & ESF & TE2 2 & 2 \\
\hline D & $\mathrm{F}$ & 34 & UBS & Enfermeira & 2 \\
\hline $\mathrm{E}$ & $\mathrm{F}$ & 34 & ESF & Enfermeira & 2 \\
\hline $\mathrm{F}$ & $\mathrm{F}$ & 35 & ESF & Enfermeira & 1 \\
\hline G & $\mathrm{F}$ & 39 & UBS & Enfermeira & 8 \\
\hline $\mathrm{H}$ & $\mathrm{F}$ & 44 & UBS & $\mathrm{TE}^{2}$ & 4 \\
\hline I & $\mathrm{F}$ & 44 & UBS & Médica & 3 \\
\hline J & $\mathrm{F}$ & 44 & ESF & ACS1 & 6 \\
\hline $\mathrm{K}$ & $\mathrm{F}$ & 47 & ESF & ACS1 & 4 \\
\hline $\mathrm{L}$ & $\mathrm{F}$ & 49 & ESF & $\mathrm{TE}^{2}$ & 9 \\
\hline$M$ & $\mathrm{~F}$ & 53 & UBS & $\mathrm{TE}^{2}$ & 1 \\
\hline $\mathrm{N}$ & $\mathrm{F}$ & 58 & ESF & Médica & 2 \\
\hline
\end{tabular}

Fonte: Os autores.

1 ACS: agente comunitário de saúde.

2 TE: técnico em enfermagem.

Quando avaliado o nível geral de estresse dos trabalhadores das unidades de saúde, foi observado que metade dos funcionários obteve resultado de nível de estresse inferior, ou seja, não apresentavam características que os classificassem naquele momento em um quadro de estresse. Os outros $50 \%$ das entrevistadas apresentaram níveis de estresse que oscilavam entre estresse médio inferior ou superior.

O segundo resultado refere-se ao nível de estresse dos trabalhadores das unidades de saúde quanto aos fatores clima e funcionamento organizacional. Os trabalhadores (56\%) sentiam-se afetados pelo clima e funcionamento organizacional existente nos seus locais de trabalho. O restante (44\%) não apresentava estresse quanto ao fator avaliado.

O terceiro resultado refere-se ao nível de estresse dos trabalhadores das unidades de saúde pesquisadas, no que concerne à pressão no ambiente de 
trabalho. Dos participantes, 60\% apresentaram estresse ocasionado pela pressão no trabalho. O restante dos participantes (40\%) não apresentou características que evidenciassem ser afetados pelas pressões do local.

O quarto e último dado é o resultado da avaliação do nível de estresse dos trabalhadores das unidades de saúde pesquisadas referente à infraestrutura do local. Para esse fator, $51 \%$ dos participantes não apresentaram nível de estresse, já 49\% dos trabalhadores sentiam-se afetados negativamente pela infraestrutura da unidade em que trabalhavam, o que tornava esses funcionários vulneráveis ao estresse, que atingiu níveis de estresse entre médio inferior e superior.

Após a leitura e a análise dos dados referentes às entrevistas, foram criadas cinco categorias: significado do trabalho; motivações para o trabalho; trabalho em equipe se faz com diálogo; o trabalho com a comunidade; e do desgaste ao prazer: as consequências do trabalho.

\section{Significado do trabalho}

Para definirmos o significado do trabalho é necessário proceder a uma rápida leitura histórica sobre a temática. Essa leitura se inicia na Antiguidade greco-romana, quando ocorre a primeira divisão do trabalho, e passa pela tradição judaico-cristã, que ainda pode estar influenciando nossos princípios. Os gregos separavam o trabalho em três formas: o labor, trabalho pela sobrevivência associado ao homem que trabalhava com a terra; a poíesis, capacidade de criação do homem; e a práxis, que é a ação propriamente dita do discurso, da política, aquela que não gera um produto, o ato acontece dentro do próprio sujeito agente. Já na tradição judaico-cristã, o trabalho era visto como algo penoso, um castigo pelos pecados, uma forma de afastar os pensamentos provocados pela preguiça e pelo ócio, e pertencente ao mundo dos mortais era imperfeito (Albornoz, 2004).

No que tange ao mundo contemporâneo, observam-se outras três características do trabalho. Segundo Albornoz (2004), a primeira é a separação entre os lugares de trabalho e de moradia: o funcionário da atualidade está distante da convivência familiar, questão que afeta sobretudo as mulheres, tradicionalmente encarregadas dos cuidados com os filhos. A segunda é a separação entre produto e produtor, a alienação do trabalho, pois o produtor não vê o conjunto da atividade em que seu esforço se insere, realiza o seu trabalho, mas não sabe por que, qual será o produto e quem irá utilizá-lo. Essa define tal fato também como uma autoalienação, pois o trabalhador vende sua energia e seu tempo para outro, vende sua personalidade, seu sorriso, sua pontualidade, aparência etc. A última característica é a que separa o trabalho do prazer, do lazer e da cultura. 
Em muitas situações e momentos da sociedade contemporânea, o trabalho e a sua ideologia se reduziram ao nível do labor, um esforço rotineiro com o objetivo de sobrevivência, como pode ser observado em algumas entrevistas:

Trabalhar, a gente trabalha porque precisa, tem que gostar do que faz, e acho que faz parte da vida da gente, trabalhar, se sentir útil (Participante H).

Trabalho é um emprego, uma atividade, um ganho em dinheiro e para mim mesmo. Não me vejo mais sem trabalhar, não importa em que, é a minha estabilidade (Participante J).

No entanto, quando o homem se torna um sujeito ativo, construtor e criador de sua realidade, passa a ser livre. Assumindo esse lugar, a relação entre homem e objeto no trabalho se modifica, une-se o subjetivo ao objetivo. Assim, a produção do objeto pelo homem é um processo de autoprodução do homem, reconhecendo-se a si mesmo e reconhecendo a relação social em que está envolvido. Isso torna o processo de trabalho significativo, prazeroso (Bavaresco, 2003).

Trabalhar significa se realizar profissionalmente, estar feliz no que se está fazendo. Eu acho que é isso. Não adianta trabalhar em algum lugar, em qualquer lugar, e, ao mesmo tempo, não se sentir feliz no que se está fazendo (...) (Participante C).

Trabalhar eu acho que é se sentir satisfeita com as atividades do dia a dia; poder desempenhar as atividades para as quais você se preparou; então, acho que trabalhar é poder desenvolver tudo que se estudou e para o que se preparou, para ajudar dentro da área em que você se formou (...) (Participante E).

É por meio do trabalho que o sujeito se representa diante da sociedade e de si mesmo, configurando sua identidade, gerando sua subjetividade. Mediante o trabalho, o sujeito estabelece e mantém relações sociais, assegura a sua sobrevivência e a conquista de seus bens materiais. Selligmann-Silva (1994) ressalta que o sujeito permanece a maior parte do tempo de sua vida no ambiente de trabalho ou envolvido em atividades referentes ao mesmo fora do seu horário de expediente. Assim, o trabalho pode significar realização, satisfação e prazer, contudo, esse mesmo trabalho, pode ser sinônimo de insatisfação e desgaste, podendo levar ao adoecimento do trabalhador.

\section{Motivações para o trabalho}

A motivação para o trabalho é um estado de espírito positivo que permite ao indivíduo o desenvolvimento de potenciais de satisfação de seus objetivos. 
Quando se trabalha com motivação, a primeira questão a ser analisada é que propósitos e motivações as pessoas têm no trabalho (Lopes, 1980).

A motivação das pessoas depende de dois fatores: higiênicos e motivacionais. De acordo com Chiavenato (2006), os fatores higiênicos referem-se às condições físicas e ambientais de trabalho, ao salário, aos benefícios sociais, às políticas da empresa, ao tipo de supervisão recebida, ao clima de relações entre a direção e os empregados, e aos regulamentos internos, entre outros. Os fatores motivadores estão ligados ao conteúdo do cargo, às tarefas e aos deveres relacionados com o cargo em si, produzindo efeitos duradouros de satisfação e um aumento de produtividade em níveis de excelência.

A respeito dessa questão, todas as entrevistadas relataram que se sentiam motivadas para a realização do seu trabalho; a diferença residia nos fatores motivacionais. Dentre os fatores de destaque, estava o reconhecimento e o retorno do trabalho investido:

O que me motiva é ver o resultado, o resultado de algum paciente de quem a gente está cuidando, ver o resultado final (...), me realiza bastante eu ver a realização do meu trabalho, quando a gente vê um resultado (Participante C).

O que me motiva no trabalho é o retorno dele (...), pessoas que não caminhavam e hoje caminham, pessoas que tiveram AVC (...), eu adoro fazer isso (Participante L).

Bavaresco (2003), utilizando a teoria de Hegel, aborda o reconhecimento por meio da autoconsciência, o saber de si, a consciência de si mesmo. A autoconsciência só se satisfaz em outra autoconsciência. É preciso que a consciência seja reconhecida por outras consciências. A autoconsciência só é autoconsciência na medida em que outros a reconhecem. Um homem só é capaz de satisfazer seus desejos, suas carências humanas, quando outro homem reconhece o seu valor humano. O homem só pode manter-se humano na relação com outros homens. A essência humana não pode se manifestar no indivíduo isolado; o indivíduo só é propriamente indivíduo quando em comunidade. E quando o indivíduo faz uso do instrumento, ou seja, o trabalho que desenvolve e o que produz em comunidade lhe geram um reconhecimento que vem do outro, de outro indivíduo humano.

O reconhecimento é a principal forma de construir espaços de saúde. Dejours (2006) utiliza a psicanálise e a psicodinâmica do trabalho para abordar essa questão. Enfatiza que a construção da identidade do sujeito permanece sempre inacabada e que, com isso, assumimos uma luta pela conquista da identidade. Essa luta acontece no social, pois o sujeito não constrói sua identidade apenas por si mesmo: ele necessita do olhar e do julgamento do outro e também do campo social. A conquista da identidade é feita em dois registros, no amor erótico e no trabalho (social). 


\section{Trabalho em equipe se faz com diálogo}

Trabalhar em equipe consiste em uma modalidade de trabalho coletivo que se configura na relação recíproca entre as múltiplas intervenções técnicas e a interação dos agentes de diferentes áreas profissionais. Por meio da comunicação, ou seja, da mediação simbólica da linguagem, dá-se a articulação entre as ações multiprofissionais e a cooperação (Peduzzi, 1998).

Esse trabalho se destaca como algo difícil, tanto entre as equipes da ESF quanto entre as das UBSs, apesar de todas as entrevistadas afirmarem possuir boa relação com a equipe a que pertenciam. Também foi enfatizada a importância do diálogo e da escuta quando se trabalha em conjunto, bem como colocar-se no lugar do outro.

É bom [o trabalho], às vezes tem algumas dificuldades, como em qualquer lugar, mas aí a gente procura se reunir, conversar e ver o que está acontecendo, o que pode melhorar, com todo mundo junto, sem que nenhuma decisão seja tomada unicamente, e a gente sempre chega a um consenso (Participante F).

Em algumas vezes [a atividade profissional] é difícil, em outras, gratificante. Eu acho que a gente tem que ter um controle emocional, um pulso firme algumas vezes, tem que dialogar bastante, tem que haver a troca de conversa, a cumplicidade dos colegas, acima de tudo o diálogo, para trabalhar em equipe (Participante A).

Não foi mencionada a inexistência de conflitos e de dificuldades; no entanto, busca-se sempre a resolução dos conflitos. As dificuldades são vistas como algo natural quando se trabalha em equipe:

Trabalhar em equipe é difícil. Eu tento fazer que seja o mais fácil possível, mas às vezes não consigo, e as coisas se complicam. Acho que trabalhar em equipe é isso: horas complicadas e horas fáceis, e a gente vai levando (Participante B).

A existência de um conflito não é um 'problema' de fato; é mais importante a forma como se trabalha esse conflito. Conflito significa existência de ideias, atitudes ou interesses antagônicos e colidentes. Como as pessoas são desiguais, os conflitos são atritos recorrentes entre diferentes indivíduos, grupos ou equipes. Dependendo da forma que o conflito em questão é trabalhado, é possível obter ganhos com o mesmo (Chiavenato, 2006).

Outro dado trazido pelas entrevistas é a importância do reconhecimento do trabalho pela própria equipe de trabalho, pois é ela que está presente no dia a dia: são essas pessoas que dividem e têm conhecimento dos problemas presentes na rotina de trabalho, do funcionamento do serviço e das características e necessidades da comunidade: 
Sinto reconhecimento pela equipe daqui; às vezes, fora daqui, a gente nota que as pessoas só mandam, mas não sabem como a gente está aqui. Então, às vezes, isso desvaloriza um pouco, sem contar o salário que poderia ser um pouquinho melhor, mas assim, no geral, eu me sinto valorizada, principalmente pela equipe daqui (Participante G).

Em relação aos conflitos, Lima, Assunção e Francisco (2002) mencionam os conflitos presentes nos relacionamentos interpessoais, especialmente entre subordinados e chefes, emergindo como fonte de tensão e sofrimento. Destacam ainda que as relações no trabalho são responsáveis pelo sofrimento e pelo prazer, repercutindo na vida dos trabalhadores na forma de preocupações, tristeza ou alegria. Gonzales (2001) salienta que a comunicação adequada, o espaço para a verbalização de dúvidas, sentimentos e sensações é fundamental para qualquer grupo que trabalhe essencialmente com pessoas. É desses momentos que retiramos a energia para o enfrentamento diário.

\section{O trabalho com a comunidade}

O trabalho com a comunidade parte do pressuposto da promoção saúde, do empoderamento dos indivíduos e das coletividades, a fim de que aumentem o controle sobre os determinantes da saúde, como emprego, renda, educação, cultura, lazer e hábitos de vida, de forma a instrumentalizar a intervenção para que ela se torne mais eficaz e efetiva sobre os mesmos. Nessa perspectiva, o Estado possui a responsabilidade de reduzir as diferenças, assegurar a igualdade de oportunidades e promover os meios que permitam a todos desenvolver um melhor controle sobre o viver, adoecer e morrer (Chiesa et al., 2007).

A fim de desempenhar esse papel, o profissional deve estar preparado para lidar com frustrações e com a falta de reconhecimento, pois, assim como o trabalho em equipe, trabalhar com a comunidade é considerada, por vezes, uma tarefa difícil e complicada, exigindo paciência e 'jogo de cintura'.

Trabalhar com a comunidade não é fácil, a comunidade vê mais os defeitos da gente do que as qualidades; você pode fazer dez coisas certas, mas se você não faz uma pra eles, basta. Então é difícil; tem que ter jogo de cintura (...) (Participante H).

Apesar dessa acomodação e da prisão da população ao antigo sistema médico, o profissional da saúde que trabalha com a comunidade deve investir, incentivar e primar pela mudança, na lógica da saúde. Spink (2007) afirma que as tarefas tradicionais não dão mais conta das demandas e que na conjuntura atual o Estado, com o auxílio de seus profissionais, tem a função de 
informar e de educar em saúde como forma de transferir responsabilidade também para o cidadão, facilitando a aquisição de autonomia pelo sujeito. Para que isso ocorra, os profissionais que realizam trabalhos em saúde comunitária devem estar envolvidos com a comunidade, devem possuir conhecimento das demandas do território, dos recursos públicos e comunitários de que dispõem para o trabalho, das ações intersetoriais e das redes de apoio existentes nas comunidades, necessárias para o desenvolvimento de sua prática.

Com essa perspectiva, o governo federal desenvolveu estratégias que vão ao encontro das necessidades problematizadas no parágrafo anterior, tendo os profissionais da saúde, juntamente com os cidadãos, como sujeitos de mudança, por meio de iniciativas como a Política Nacional de Educação Permanente em Saúde, estratégia fundamental para as transformações do trabalho no setor, a fim de que venha a ser um espaço de atuação crítica, reflexiva, propositiva, compromissada e tecnicamente competente (Ceccim, 2005). Há também os núcleos de excelência, como por exemplo o Programa de Reorientação na Formação dos Profissionais da Saúde (Pró-Saúde), que têm por objetivo formar profissionais críticos e reflexivos em relação às necessidades da população brasileira, com habilidades e competências que possibilitem o interagir no processo saúde-doença, considerando os princípios do Sistema Único de Saúde (SUS) e programas como o PET-Saúde (Brasil, 2004).

Às vezes é meio difícil, meio complicado, porque nem sempre eles (a comunidade) querem palestra e orientações; eles querem consultas, e se não saem com uma receita na mão, acham que aquilo não é saúde. Nos grupos, muitas vezes a gente vai com todo o gás e chega lá tem uma meia dúzia, falta adesão (Participante N).

Conforme Góis (2008), os dois principais campos de atuação em saúde comunitária são a participação dos profissionais de saúde no processo de desenvolvimento comunitário e a ação diferencial tomando como referência o ciclo vital. No primeiro âmbito, os profissionais são situados na esfera de desenvolvimento da comunidade, envolvendo-os com as principais questões ou problemas vividos pela população. O profissional deixa de ser um técnico de ação específica, isolado, fechado em um posto de saúde, para ser um profissional que participa dos anseios e práticas comunitárias nas diversas áreas das necessidades da comunidade.

Eu costumo dizer que é a pessoa, o profissional que vai tornar difícil o convívio com qualquer comunidade, é o profissional que vai definir se vai ter uma boa relação com a comunidade. Quando se dá chance a essa pessoa de vir colocar os problemas que ela tem e está sentindo, acaba-se desenvolvendo um vínculo, certo respeito (Participante E). 
O compromisso e a participação ativa geram indivíduos atuantes, agentes de mudança, com uma participação que vai além da colaboração. Essa é a prática que deve ser desenvolvida pelos profissionais, uma prática que trabalhe com o compromisso, ou seja, com a consciência, com um sentimento de obrigação e respeito em relação à causa defendida, que faça gerar mobilização e assim crescimento do indivíduo.

\section{Do desgaste ao prazer: as consequências do trabalho}

O trabalho constitui elemento fundamental da existência humana. Pode contribuir para o bem-estar ou para a manifestação de sintomas que afetam a saúde. A organização do trabalho é considerada uma mediadora desse processo. Ela é compreendida como divisão do trabalho, incluindo a divisão das tarefas, sua repartição, a definição das cadências, o modo operatório prescrito, e divisão de homens, com repartição de responsabilidades, hierarquia, comando e controle (Dejours, Abdoucheli e Jayet, 1994).

As consequências do trabalho na saúde das profissionais entrevistadas ocorrem na saúde global, no âmbito físico e emocional, com destaque para as consequências emocionais. As profissionais percebem-se afetadas pelo trabalho, com um sofrimento que permanece e se estende nas relações de trabalho e pessoais.

(...) Percebo pela irritabilidade, isso afeta bastante a gente, deixa bastante estressada, irritada e acaba afetando os colegas também; não o físico, mas mais o psicológico, tem um cansaço na mente, e eu acabo tendo pouca paciência (Participante C).

Eu noto que eu perco o sono pensando nos problemas, eu sinto que estou precisando fazer essa ginástica laboral, estou precisando para relaxar, a fisioterapeuta me ajuda às vezes (Participante $\mathrm{N}$ ).

Em relação a essa sintomatologia, Selligmann-Silva (1994) afirma que a falta de reconhecimento, o bloqueio do desenvolvimento da identidade e a baixa autoestima levam ao desgaste dos trabalhadores. As manifestações desse desgaste são cansaço, alta irritabilidade, desânimo e sono perturbado que caracterizam a fadiga patológica e podem levar a crises mentais agudas. A esse processo, vincula-se o medo subjacente à ansiedade, ou seja, o medo de sofrer acidente e do esgotamento. O esforço para controlar o medo é extremamente desgastante.

Também na sintomatologia, Filgueiras e Hippert (2002) afirmam que os sintomas físicos do estresse mais comuns são fadiga, dores de cabeça, insônia, 
dores no corpo, palpitações, alterações intestinais, náuseas, tremores, extremidades frias e resfriados constantes. Os sintomas psíquicos, nomeados pelos autores como mentais e emocionais, referem-se à diminuição da concentração e da memória, indecisão, confusão, perda do senso de humor, ansiedade, nervosismo, depressão, raiva, frustração, preocupação, medo, irritabilidade e impaciência.

Dentre as doenças físicas, as doenças por esforços repetitivos receberam destaque. Casos de lesões por esforço repetitivo (LER) são comuns em algumas profissões, como entre os enfermeiros e técnicos de enfermagem:

Tendinite é uma das doenças que eu tenho na mão, por causa das vacinas [que aplica] e outros movimentos; estou atacada da asma por questões emocionais, mas agora já estou medicada (Participante A).

Eu tenho tendinite no punho de tanto escrever e, no psicológico, é aquela coisa da pressão, de ter que fazer, fazer, fazer, fazer, e não te dão valor. Então, de vez em quando, a gente diz que vai pirar, vou enlouquecer, então, [isso] afeta com certeza (Participante G).

No entanto, Dejours (1992) destaca que existem casos em que o trabalho é favorável à saúde mental e à saúde do corpo, proporcionando uma resistência maior contra a fadiga e a doença. Logo, para esse autor, a adequação entre a organização do trabalho e a estrutura mental do trabalhador é possível quando se levam em conta duas condições: uma refere-se às exigências intelectuais, motoras ou psicossensoriais da tarefa, que devem estar de acordo com as necessidades do trabalhador, e a outra, ao conteúdo do trabalho, que deve ser fonte de uma satisfação sublimatória. O trabalhador pode, então, modificar a organização do trabalho conforme o seu desejo ou as suas necessidades, ou pode até fazê-las variar, conforme seu próprio ritmo. Dejours (1992) salienta que num trabalho livremente escolhido ou livremente organizado o trabalhador tem suas vias de descarga mais adaptadas às suas necessidades, consequentemente o trabalho torna-se um meio de relaxamento que, muitas vezes, faz com que o trabalhador se sinta melhor do que antes, ao ver a sua tarefa terminada, fazendo do trabalho sua melhor defesa. Isso pode ser percebido na fala a seguir, quando uma das entrevistadas é questionada sobre as consequências do trabalho para a sua saúde:

De ruim não, só de melhor, só coisa positiva. Eu me sinto motivada, viva, eu estou fazendo alguma coisa que dá retorno, eu venho aqui e sei que vou fazer uma coisa que vai resultar em alguma coisa. Eu me sinto, assim, motivada para fazer mais (Participante D). 


\section{Considerações finais}

Pelos resultados obtidos na pesquisa, foi possível verificar não apenas a influência do trabalho na saúde mental dos profissionais pesquisados, como também a sua ambiguidade no que tange aos resultados que ele tem na subjetividade dos sujeitos, reforçando teorias que o classificam ora como estruturante ora como desestruturante (Dejours, Abdoucheli e Jayet, 1994).

São muitos os fatores que devem ser conjugados ao se trabalhar a saúde mental do trabalhador, pois ao pensar em saúde do trabalhador é preciso pensá-la por inteiro, contemplando promoção, prevenção, assistência à reabilitação e vigilância à saúde. Pensar o trabalho nesse sentido nos leva a compreender a vivência subjetiva do processo de trabalho, as condições do trabalho e suas repercussões nos trabalhadores. Dentre elas, o processo de produção e as relações sociais de trabalho são da maior importância, pois são os principais geradores de realização e, quando em desequilíbrio, podem levar ao adoecimento físico e, principalmente, psíquico (Centro de Referência Técnica em Psicologia e Políticas Públicas, 2008).

Cabe lembrar que é possível estabelecer relações de trabalho sem degradar as condições humanas. No entanto, quando isso não é possível, existem meios para não adoecer: são as estratégias de enfrentamento, formas de defesa criadas pelos trabalhadores ante o sofrimento causado por determinada situação (Dejours, Abdoucheli e Jayet, 1994). Não existe uma receita específica e geral, essas estratégias devem ser construídas de acordo com as necessidades e possibilidades de cada pessoa ou grupo de trabalho.

Com isso, é possível perceber a íntima relação que existe entre trabalho e saúde mental e a importância e a necessidade da realização de um trabalho que aborde essas questões com os profissionais de saúde, na perspectiva de cuidar da saúde de quem cuida, criando conjuntamente estratégias de enfrentamento coletivas ou individuais que se adéquem às realidades e necessidades dos trabalhadores.

\section{Colaboradores}

Eloísa Cerutti Martellet responsabilizou-se pela realização da pesquisa e redação do manuscrito. Roberta Fin Motta e Adriana Dornelles Carpes orientaram a autora principal na realização deste trabalho. 
Resumen Estudio cualitativo que tuvo como objetivo abordar el cuidado a los profesionales que trabajan en unidades de salud, en particular los impactos, los significados y las relaciones en el trabajo, además de la vulnerabilidad al estrés del trabajo. La investigación se realizó en la ciudad de Santa María, estado de Rio Grande do Sul (Brasil), con una muestra de 14 participantes de cinco unidades de salud. Los datos fueron recolectados a través de entrevistas, observaciones y pruebas, y posteriormente analizados mediante el análisis de contenido. Como resultado, el trabajo se presenta unas veces de forma estructurante, es decir, un operador fundamental en la constitución del sujeto, y otras desestructurante, capaz de desestabilizar la identidad y la personalidad y causar enfermedades mentales. Las motivaciones, la relación con la comunidad y el diálogo en las relaciones de trabajo, así como la necesidad de acciones con los profesionales de la salud, con la visión de cuidar de la salud de quien cuida, fueron consideradas fundamentales en la relación salud mental y trabajo.

Palabras clave subjetividad; salud; trabajo; educación.

\section{Notas}

1 Especialista (MBA) em Gestão de Pessoas e Marketing pela Faculdade Metodista de Santa Maria.<eloisa.cerutti@hotmail.com>

Correspondência: Rua José Canellas, n. 220, apto. 402, Frederico Westphalen, CEP 98400-000, Rio Grande do Sul, Brasil.

2 Centro Universitário Franciscano, Santa Maria, Rio Grande do Sul, Brasil.

Doutoranda em Psicologia pela Pontifícia Universidade Católica do Rio Grande do Sul. <roberta.fm@hotmail.com>

3 Centro Universitário Franciscano, Santa Maria, Rio Grande do Sul, Brasil.

Doutora em Química Orgânica pela Universidade Federal de Santa Maria.

<carpes.ad@gmail.com>

4 A pesquisa foi financiada pelo Programa de Educação pelo Trabalho para a Saúde (PET-Saúde) da Secretaria de Gestão do Trabalho e da Educação na Saúde, Ministério da Saúde. Foi aprovada pelo Comitê de Ética da Secretaria Municipal de Saúde da cidade de Santa Maria, Rio Grande do Sul, sob registro n. 0768/2009/SMS/Nepes. 


\section{Referências}

ALBORNOZ, Suzana. O que é trabalho. 6. ed. São Paulo: Brasiliense, 2004.

BARDIN, Laurence. Análise de conteúdo. 3. ed. Lisboa: Edições 70, 2004.

BAVARESCO, Agemir. A fenomenologia da opinião pública: a teoria hegeliana. São Paulo: Loyola, 2003.

BRASIL. Conselho Nacional de Saúde. Resolução n. 466, de 12 de dezembro de 2012. Aprova as diretrizes e normas regulamentadoras de pesquisas envolvendo seres humanos. Disponível em <http://conselho. saude.gov.br/resolucoes/2012/reso466.pdf>. Acesso em: 15 jun. 2014.

BRASIL. Ministério da Saúde. Secretaria de Gestão do Trabalho e da Educação na Saúde. Departamento de Gestão na Saúde. Educar SUS: notas sobre o desempenho na saúde, período de janeiro de 2003 a janeiro de 2004. Brasília: Ministério da Saúde, 2004.

BRASIL. Portaria interministerial n. 421, de 3 de março de 2010. Institui o Programa de Educação pelo Trabalho para a Saúde (PET-Saúde). Ministério da Saúde, Brasília, DF, Diário Oficial da União, 2010. Disponível em: <www.brasilsus.com.br/legislacoes/ inter-ministerial/103143-421.html > . Acesso em: 15 jun. 2014.

CECCIM, Ricardo B. Educação permanente em saúde: descentralização e disseminação de capacidade pedagógica na saúde. Ciência \& Saúde Coletiva, Rio de Janeiro, v. 10, n. 4, p. 975-986, out./dez. 2005. Disponível em: $<$ www.scielo.br/scielo.php?script $=$ sci_ arttext\&pid $=$ S1413-81232005000400020\& lng=pt\&nrm=iso > . Acesso em: 16 abr. 2014.

CENTRO DE REFERÊNCIA TÉCNICA EM PSICOLOGIA E POLÍTICAS PÚBLICAS (CREPOP). Saúde do trabalhador no âmbito da saúde pública: referências para a atuação do(a) psicólogo(a). Brasília: Conselho Federal de Psicologia, 2008. Disponível em: <http:// crepop.pol.org.br/novo/wp-content/uploads/ 2010/11/saude_do_trabalhador_COMPLETO. pdf>. Acesso em: 16 abr. 2014.

CHIAVENATO, Idalberto. Recursos humanos. 4. ed. São Paulo: Atlas, 1990.

CHIAVENATO, Idalberto. Recursos humanos: o capital humano das organizações. 8. ed. São Paulo: Atlas, 2006.

CHIESA, Anna M. et al. A formação de profissionais da saúde: aprendizagem significativa à luz da promoção da saúde. Cogitare Enfermagem, São Paulo, v. 12, n. 2, p. 236240, abr./jun. 2007.

DEJOURS, Christophe. A loucura do trabalho: um estudo de psicopatologia do trabalho. 5. ed. São Paulo: Cortez, 1992.

DEJOURS, Christophe. A banalização da injustiça social. 7. ed. Rio de Janeiro: Fundação Getulio Vargas, 2006.

DEJOURS, Christophe; ABDOUCHELI, Elisabeth; JAYET, Christian. Psicodinâmica do trabalho: contribuições da escola dejouriana à análise da relação prazer, sofrimento e trabalho. São Paulo: Atlas, 1994.

FILGUEIRAS, Júlio C.; HIPPERT, Maria I. Estresse: possibilidades e limites. In: JACQUES, Maria G.; CODO, Wanderley (Org.). Saúde mental e trabalho: leituras. Petrópolis: Vozes, 2002. p. 112-129.

GÓIS, Cezar W. L. Saúde comunitária: pensar e fazer. São Paulo: Aderaldo \& Rothschild, 2008 .

GONZALES, Rosa M. B. Sofrimento na práxis da enfermagem: real ou deslocado em seu sentido?. Florianópolis: Pós-graduação em Enfermagem da Universidade Federal de Santa Catarina, 2001.

LEOPARDI, Maria T. et al. Metodologia da pesquisa na saúde. Florianópolis: Pós-graduação 
em Enfermagem da Universidade Federal de Santa Catarina, 2002.

LIMA, Maria E. A.; ASSUNÇÃO, Ada A.; FRANCISCO, João M. Aprisionado pelos ponteiros de um relógio: o caso de um transtorno mental desencadeado no trabalho. In: JACQUES, Maria G.; CODO, Wanderley (Org.). Saúde mental e trabalho: leituras. Petrópolis: Vozes, 2002. p. 209-246.

LOPES, Tomás V. M. Motivação no trabalho. Rio de Janeiro: Fundação Getúlio Vargas, 1980.

MINAYO, Maria C. S. O desafio do conhecimento: pesquisa qualitativa em saúde. 11. ed. São Paulo: Hucitec; Rio de Janeiro: Abrasco, 2008.

PEDUZZI, Marina. Equipe multiprofissional de saúde: a interface entre trabalho e interação. 1998. 254f. Tese (Doutorado em Saúde Coletiva) - Faculdade de Ciências Médicas, Universidade Estadual de Campinas, Campinas, 1998.
SAMPAIO, Jáder R. Psicologia do trabalho em três faces. In: GOULART, Iris B.; SAMPAIO, Jáder R. (Org.). Psicologia do trabalho e gestão de recursos humanos: estudos contemporâneos. São Paulo: Casa do Psicólogo, 1998. cap. I.2.

SCARPARO, Helena (Org.). Psicologia e pesquisa. 2. ed. Porto Alegre: Sulina, 2008.

SELLIGMANN-SILVA, Edith. Desgaste mental no trabalho dominado. Rio de Janeiro: Cortez, 1994.

SPINK, Mary J. P. (Org.). A psicologia em diálogo com o SUS: prática profissional e produção acadêmica. São Paulo: Casa do Psicólogo, 2007.

Recebido em 29/06/2012

Aprovado em 11/11/2013 